\title{
I worry
}

\author{
Stephen Hancocks OBE \\ Editor-in-Chief
}

The BDJ Upfront section includes editorials, letters, news, book reviews and interviews. Please direct your correspondence to the News Editor,

Kate Quinlan at k.quinlan@nature.com. Press releases or articles may be edited, and should include a colour photograph if possible.

$\mathrm{P}$ eople who know me well would agree that by and large I am an optimist. I am a glass half full person. As a schoolboy, I recall being told that I was 'cheerful' having a smile on a good day and even a wry grin on a bad day. So, I write this editorial with a sense of concern not only because of the subject itself but because it goes against the grain of my being.

NHS dentistry, in England at least, is in a pickle and it is difficult to visualise how it is going to emerge from the current maelstrom. The situation has been compounded over many years, particularly with the energy- and morale-draining current contract utilising units of dental activity (UDAs) enforced on the profession in 2006 and most recently the exigencies of dealing with the COVID19 pandemic. But the real problems have dogged the service for many years prior to that with politicians, as well as we ourselves, often unclear in our thinking and ambivalent towards what sort of service should be provided, by who and at what price. Indeed, from shortly after the beginning of the NHS, dentistry was slapped with patient charges, completely (and at the time uniquely) undermining the philosophy of treatment being free at the point of delivery.

I have kept a diary for over 50 years now and had occasion recently to look back and read some entries from my sixth-form days. At that time, I worked on Saturday mornings as a 'dental nurse' in the practice of our family dentist. Astonishingly, here is the relevant part of the entry for Saturday 27 March 1971: '...he [the practice owner] was moaning about the lack of trade due to increased patient charges on 1st April.' It seems quite extraordinary to me that as a profession composed of university-educated, entrepreneurial individuals, it is taking us so long to find a solution - effectively most of my lifetime. It seems just as extraordinary to me that politicians have not been able to fathom out an equitable direction either. I have written here previously about how there is a complete absence of political will in relation to dentistry. This at a time when there are daily reports of dentists leaving the NHS, of ever-lengthening waiting lists for appointments and patients having to travel many miles to access care. The mailboxes of MPs are allegedly stuffed with complaints from their constituents about this crisis and yet the prime minister remains able to seemingly pass it off with claims that more money has been poured into the NHS, sidestepping that none has been wafted anywhere near dentistry.

I also worry about the public perception of what we do. There has not, to my

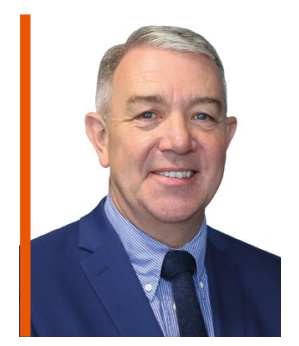

\section{'We should also not forget that we are individual contractors and as such our livelihood is in our own hands.'}

am reminded of the exodus of practitioners from the NHS in the early 1990s following the debacle of the, then, new contract. How many of them ever gravitated back? If you did, we would be fascinated to hear your story. Also, looking back, we should also be mindful of the fate of the world of opticians since that service was effectively annexed from the NHS at the end of the last century. How are they doing?

A plethora of other factors feed into this bizarre scenario. For young dentists, the prospect of a life shackled with UDAs is at best unappealing and at worst to be avoided completely; and the popularly expressed opinion is one of sympathy to this stance. The likelihood of team members leaving knowledge, been a single mention of patients complaining throughout the pandemic about where they can get preventive advice. Treatment for pain, yes; cosmetic dentistry, yes. We need to seriously consider how this reflects on the service we are seen to be delivering and if and how we want this to change in the future.

The Treasury, as well as collecting a tranche of income from patient charges, does also pump billions of pounds into the dental NHS. We should not forget this, but we should also not forget that we are individual contractors and as such our livelihoods are in our own hands. An increasing move of colleagues towards provision of private care either directly or through third-party agencies is manifest. I the profession because of not wanting to be vaccinated compulsorily against COVID-19 by 1 April 2022 is a present consideration. So too is the continuing need to employ a range of anti-coronavirus protections including sometimes onerous personal protections.

I wish I had some more practical answers but I do not; other than I believe increasingly that the future of each of us lies in our own hands, albeit within the collective and supportive strength of professional colleagues. I think it unlikely that I will be able to make a diary entry for 27 March 2071 but I also think that it would be very different from that a century earlier. For worse and for better, it will be resolved; but in the meantime, I worry.

https://doi.org/10.1038/s41415-022-3885-7 